\title{
Special Issue: Phonological and phonetic variation in spoken morphology
}

\author{
Ruben van de Vijver $^{1}$ (D) Fabian Tomaschek ${ }^{2}$ (D)
}

Received: 4 February 2021 / Accepted: 11 February 2021 / Published online: 24 February 2021

(C) The Author(s) 2021

\begin{abstract}
In recent years, more and more evidence is accumulating that there is a great deal of variation as a result of morphological complexity, both at the level of phonology and at the level of phonetics. Such findings challenge established linguistic models in which morphological information is lost in comprehension or production. The present Special Issue presents five studies that investigate the phenomenon in more detail, centered around the following questions: How do morphological relations affect articulatory and phonological properties of complex words? How do articulatory and phonological properties of complex words reflect their morphological relations? What do these two questions imply about theories that address morphological relatedness at the level of sounds?
\end{abstract}

Keywords Spoken morphology $\cdot$ Phonetic variation $\cdot$ Variation

\section{Spoken morphology: Phonetic and phonological variation in the realization of morphology}

Psycho-linguistic and formal theories dealing with morphology at the level of sounds assume that morphological structure is categorical (e.g. Bermúdez-Otero 2008; Levelt et al. 1999; Roelofs 1997; Zwitserlood 2018). For example, morphological complex words such as 'walks' or 'goes' are bimorphemic, with a morphological boundary between the stems 'walk' and 'go', and the inflectional suffix '-s'. By contrast,

F. Tomaschek

fabian.tomaschek@uni-tuebingen.de

R. van de Vijver

ruben.vijver@uni-duesseldorf.de

1 Institut für Sprache und Information, 24.53.00.98, Heinrich-Heine-Universität, Universitätsstr. 1, 40225 Düsseldorf, Germany

2 Seminar für Sprachwissenschaft, R. 3.19, Universität Tübingen, Wilhelmstraße 19-23, 72074 Tübingen, Germany 
morphological simple words such as 'guess' or 'gas' are monomorphemic without a boundary preceding the ' $s$ '. Since the word final ' $\mathrm{s}$ ' is mapped in both cases on the identical phoneme /s/, the phonetic realization of the final [s] in these words is not supposed to be affected by their morphological structure or its function. Yet, recent findings call this central assumption into question.

There is a great deal of variation as a result of morphological complexity, both at the level of phonology and at the level of phonetics. To give two brief illustrative examples: the word comparable can be pronounced with stress on the first syllable, cómparable, or with stress on the second syllable, compárable. Bauer et al. (2013) show that many words suffixed with -able show such stress variation. Collie (2008) argues that frequency plays a role in variable stress placement in complex words. Lower frequency of the morphologically complex word and higher frequency of the morphologically simple word favor preservation of the stress pattern of the simple word. Higher frequency of the morphologically complex word and lower frequency of the morphologically simple word do not favor preservation of the stress pattern of the simple word. Such variation is not predicted by theories that view relations among morphologically related words as invariable. At the phonetic level, it has been shown that the lexical frequency of derived words affects its pronunciation. The $/ t /$ in the very frequent word exactly is easily elided, whereas the / $t /$ in the infrequent abstractly is often pronounced (Hay 2001, 2003). This effect, too, is not predicted by theories that assume strict categoricality.

The variation that has been reported in the literature not only reflects the morphological structure of a word, but also the type of morphological relation among words. For example, Plag et al. (2017) find that the duration of word-final /s/ in American English is longest in morphologically simple words, a bit shorter when $/ \mathrm{s} /$ is affiliated with a suffix and still a bit shorter when it is affiliated with a clitic. However, it is not just morphological complexity that affects variation. It is also affected by the type of morphological relation among words. Seyfarth et al. (2018) compares the duration of $/ \mathrm{z} /$ in homophones, one of which is morphologically complex, such as free-s and freeze. The $/ \mathrm{z} /$ in free-s is a bit longer than in freeze, since the duration of $/ \mathrm{z} /$ in free-s is affected by the duration of the of the simple word free, which is slightly longer than the string /fri:/ in freeze.

In conclusion, categorical theories of morphophonology have been confronted with variable data that they have difficulty accounting for. The variation reported in the literature reflects morphological complexity and the type of morphological relatedness, and therefore goes to the heart of morphophonological theory. The aim of the special issue is therefore to collect papers that focus on spoken morphology in terms of providing both, a richer set of phonetic phenomena, and a more thorough theoretic account.

\section{How do the papers in the special issue contribute to morphological theory}

By offering new and unexplored data and theories accounting for these data, the papers in this issue contribute to three central questions in morphological theory: 
a) How do morphological relations affect articulatory and phonological properties of complex words?

b) How do articulatory and phonological properties of complex words reflect their morphological relations?

c) What do these two questions imply about theories that address morphological relatedness at the level of sounds?

We will explain briefly how these questions relate to the papers in the special issue.

Bell, Ben Hedia \& Plag test two hypotheses concerning reduction or strengthening at morphological boundaries. One hypothesis is that segments at boundaries in complex words that are easy to decompose are longer. The other hypothesis is that if a segment at a boundary is more predictable it is also longer. They investigated the duration of the linking consonant in English NN compounds. They found that the consonant is longer in compounds with a smaller N1 family size, supporting the predictability hypothesis, but not the segmentability hypothesis. In doing so, they address questions (b) and (c) in their paper.

Morrison asks the question whether the effect of initial mutation in Scottish Gaelic is an example of incomplete neutralization, in which phonetic traces of morphologically related words can be detected. In Scottish Gaelic initial /p, m/ both lenite to $[\mathrm{v}]$ in certain morphologically determined conditions. He asked native speakers to read out a word list and Morrison measured the nasal airflow during reading. It turns out that there is no evidence for nasalization of lenited [v]. He concludes that the phonetic highlighting of morphological relatedness does not go so far as to induce a lowering of the velum. In doing so, Morrison addresses question (a).

Nieder \& van de Vijver \& Mitterer investigate the complex singular-plural mappings in the Semitic language Maltese, which has a concatenative and a nonconcatenative morphology. In addition to many possible ways to map a singular onto a plural form, there are, for a sizable amount of singulars, multiple possible mappings onto plurals. In a production study in which native speakers were asked to produce plurals for given existing and nonsense singulars, they found that the segmental makeup of the singular - its phonotactics - determines to a large extent which plural form is preferred. The patterns produced by native speakers were best modeled by associative learning models. This contribution, too, addresses how morphological relations affect complex words (question (a)) and propose an answer to question (c).

Tomaschek, Tucker, Ramscar \& Baayen use electromagnetic articulography to study the position of the tongue during the articulation in monosyllabic uninflected and inflected American English verbs. They investigate how lemma frequency, word form frequency and paradigmatic probability - word frequency divided by lemma frequency - modulated articulation of the stem vowel. They find that paradigmatic probability is the best predictor for articulatory movements. Furthermore, they find that higher paradigmatic is associated with more enhanced articulatory movements supporting the Paradigmatic Enhancement Hypothesis (Kuperman et al. 2007). In this way, Tomaschek, Tucker, Ramscar \& Baayen address how morphological relations among words affects the pronunciation of segments (question (b)) and the question as to the consequences for morphological theory (question (c)).

Zuraw, Lin, Yang \& Peperkamp study competition between whole word and decomposed representations of English prefixed words. Voiceless stops following $s$ 
are usually unaspirated, yet they can be aspirated if the $s$ belongs to a prefix and the stop belongs to a stem. They find that stops are more likely to be aspirated if the stem is frequent and the whole word is infrequent, and that stops are less likely to be aspirated if the whole word is frequent and the stem is infrequent. This finding is in line with competition between whole-word access and decomposed access (Hay 2003). They then use a priming experiment to test whether there is evidence for whole-word access and decomposed lexical access. In doing so they address question (a) and (c).

In short, all papers address variation in the pronunciation of morphologically related words, and all address central questions that arise from this variation.

Acknowledgements We thank Olivier Bonami for his help during the preparation of this special issue. This research was funded by the Deutsche Forschungsgemeinschaft (Research Unit FOR2373 'Spoken Morphology', Projects VI 223/3-1, VI 223/3-2, BA 3080/3-1 and BA 3080/3-2), which we gratefully acknowledge.

Funding Note Open Access funding enabled and organized by Projekt DEAL.

Publisher's Note Springer Nature remains neutral with regard to jurisdictional claims in published maps and institutional affiliations.

Open Access This article is licensed under a Creative Commons Attribution 4.0 International License, which permits use, sharing, adaptation, distribution and reproduction in any medium or format, as long as you give appropriate credit to the original author(s) and the source, provide a link to the Creative Commons licence, and indicate if changes were made. The images or other third party material in this article are included in the article's Creative Commons licence, unless indicated otherwise in a credit line to the material. If material is not included in the article's Creative Commons licence and your intended use is not permitted by statutory regulation or exceeds the permitted use, you will need to obtain permission directly from the copyright holder. To view a copy of this licence, visit http://creativecommons.org/licenses/by/4.0/.

\section{References}

Bauer, L., Lieber, R., \& Plag, I. (2013). The Oxford reference guide to English morphology. Oxford, UK: Oxford University Press.

Bermúdez-Otero, R. (2008). Stratal optimality theory. Oxford studies in theoretical linguistics. Oxford, UK and Cambridge, MA: Oxford University Press.

Collie, S. (2008). English stress preservation: A case for stratal optimality theory. Unpublished PhD dissertation, University of Edinburgh.

Hay, J. (2001). Lexical frequency in morphology: Is everything relative? Linguistics, 39(6), 1041-1070.

Hay, J. (2003). Causes and consequences of word structure. London: Routledge.

Kuperman, V., Pluymaekers, M., Ernestus, M., \& Baayen, H. (2007). Morphological predictability and acoustic salience of interfixes in Dutch compounds. The Journal of the Acoustical Society of America, 121, 2261-2271.

Levelt, W. J., Roelofs, A., \& Meyer, A. S. (1999). A theory of lexical access in speech production. Behavioral and Brain Sciences, 22(1).

Plag, I., Homann, J., \& Kunter, G. (2017). Homophony and morphology: The acoustics of word-final S in English. Journal of Linguistics, 53(1), 181-216.

Roelofs, A. (1997). The WEAVER model of word-form encoding in speech production. Cognition, 64(3), 249-284.

Seyfarth, S., Garellek, M., Gillingham, G., Ackerman, F., \& Malouf, R. (2018). Acoustic differences in morphologically-distinct homophones. Language, Cognition and Neuroscience, 33(1), 32-49.

Zwitserlood, P. (2018). Processing and representation of morphological complexity in native language comprehension and production. In G. Booij (Ed.), The construction of words (pp. 583-602). Berlin: Springer. 